\title{
Contexto Histórico e as influências na formação de Bento Munhoz da Rocha.
}

\begin{abstract}
Renê Wagner Ramos ${ }^{1}$
Resumo: O artigo discorrerá sobre como a origem familiar, acadêmica e política de Bento Munhoz da Rocha Filho, em consonância com as imbricações produzidas pela proximidade com a política e economia permitiu a formação de alianças políticas e as transformações econômicas que ocorriam no início do século XX. Analisaremos como momento ascensão de Caetano Munhoz da Rocha (Pai de Bento Munhoz) como político regional representante da indústria do Mate e a aliança política com Affonso de Camargo representante da oligarquia proprietária do chamado Paraná Tradicional. Como essa aliança impactará no discurso de Bento Munhoz da Rocha na condição de intelectual em suas idéias e principalmente como governador. Acerca da política agrária, da Reforma Agrária, do cooperativismo, da agro-indústria, da democracia, do comunismo, as questões sociais como o mundo trabalho que estão presentes em discursos, textos, artigos, livros e outros documentos arquivados no Museu Paranaense e no Círculo Bandeirante. E, finalmente contextualizaremos os anos de 1920 a 1951, na perspectiva política e econômica do Paraná em suas relações com a crise do Mate, o avanço da economia cafeeira e suas consequências no universo político paranaense.
\end{abstract}

Palavras Chaves: Bento Munhoz da Rocha. Família. Política. Economia.

\section{Historical Context and the influences on the formation of Bento Munhoz da Rocha}

\begin{abstract}
The article will discuss how the family, academic and political origin of Bento Munhoz da Rocha Filho, in consonance with the imbrications produced by proximity to politics and economics, allowed the formation of political alliances and the economic transformations that occurred at the beginning of the 20th century. We will analyze the moment ascent of Caetano Munhoz da Rocha (Father of Bento Munhoz) as regional politician representative of the Mate industry and the political alliance with Affonso de Camargo representative of the oligarchy owning the so-called Paraná Tradicional. How this alliance will impact the discourse of Bento Munhoz da Rocha as an intellectual in his ideas and mainly as governor. About agrarian policy, Agrarian Reform, cooperativism, agro-industry, democracy, communism, social issues such as the work world that are present in speeches, texts, articles, books and other documents filed in the Museu Paranaense and in the Círculo Bandeirante. And finally, we will contextualize the years from 1920 to 1951 , in the political and economic perspective of Paraná in its relations with the Mate crisis, the advancement of the coffee economy and its consequences in the political universe of Paraná.
\end{abstract}

Key Words: Bento Munhoz da Rocha, Family, Politics, Economics.

*Enviado em 29/04/2018.

*Aceito em 05/06/2018.

Relações Familiares, Formação acadêmica e política.

Nesse artigo apresentaremos a origem familiar, a formação acadêmica e política de Bento Munhoz da Rocha Filho analisando a situação familiar e suas imbricações com poder político e

\footnotetext{
${ }^{1}$ Pesquisador do Museu Paranaense; Doutorando em História pela UPF (2015-2019); Mestre em História pela UPF
} (2005). 
econômico permitirá compreender as alianças políticas e as transformações econômicas que ocorriam no início do século XX, no momento histórico da ascenção de Caetano Munhoz da Rocha (Pai de Bento Munhoz) como político regional representante da indústria do Mate e a aliança política com Affonso de Camargo representante da oligarquia proprietária do chamado Paraná Tradicional. Como essa aliança impactará na postura adotada por Bento Munhoz da Rocha na condição de intelectual em suas idéias e principalmente como governador.

Identificamos e analisamos os conceitos defendidos pelo ex-governador acerca da política agrária, da Reforma Agrária, os conceitos de Cooperativismo, da agro-industrialização, democracia, comunismo, as questões sociais como o mundo trabalho que estão presentes em discursos, textos, artigos, livros e outros documentos arquivados no Museu Paranaense e no Círculo Bandeirante. Que foram adotadas na condição de governador do Estado do Paraná na implementação de sua política agrária com a implantação de novo modelo de produção agrário instituído em colônias de imigrantes em um sistema cooperativista agroindustrial tese central desse trabalho de pesquisa.

Ainda identificamos e analisamos as concepções políticas e ideológicas em temas centrais para analisarmos o pensamento e a ações do ex-governador como intelectual e governador como questões como; Democracia, comunismo, questão Agrária, Imigração, colonização, Situação Política, Econômica e Social 1900. E, finalmente contextualizaremos os anos de 1920 a 1951, na perspectiva política e econômica do paraná em suas relações com a crise do Mate, o avanço da economia cafeeira e suas consequências no universo político paranaense

\section{Origens Familiares e política.}

A família de Munhoz da Rocha, desembarcou em Paranaguá, nos fins do século XVIII, provenientes de Cadiz (Espanha), o patriarca Bento Antonio Munhoz e sua esposa Michelina Assumpção. A família mais especificamente, o neto do casal, Caetano José Munhoz enriqueceu nos negócios do mate. Foi um dos pioneiros na adoção do vapor e no beneficiamento do mate. Os negócios continuaram prosperando em torno da exportação com seu filho Bento Munhoz da Rocha, e mais adiante dos seus filhos Caetano Munhoz da Rocha e Ildefonso Munhoz da Rocha, sendo que Caetano Pai do ex-governador Bento Munhoz da Rocha Neto, enveredou-se pela política estadual, ocupando vários cargos eletivos de prefeito, deputado a presidente da província entre 1920-1928. (REBELO, 2005, p. 15).

Eram imigrantes não possuíam títulos de nobreza e não pertenciam a elite econômica. Mas o avô de Bento Munhoz enriqueceu com o negócio do Mate possibilitando ao filho Caetano Munhoz 
da Rocha, pai de Bento, dedicar-se aos estudos e formar-se em medicina no Rio de Janeiro e a construir uma carreira política. Foi prefeito de Paranaguá, Vice-presidente e presidente do Estado.

O Pai, Caetano exerceu a profissão de médico por um período breve, chegando a clinicar na Santa Casa de Misericórdia de Paranaguá. Foi atraído para a carreira política, filiou-se Partido Republicano, elegendo-se deputado Estadual em 1904, sendo reeleito em três legislaturas até 1915, ano em que acumulou a função de prefeito de Paranaguá entre 1908 e 1915, na época era permitido pela legislação. (REBELO, 2005, p. 17).

Bento nasceu em Paranaguá, em uma casa confortável em 17 de dezembro de 1905, na rua Julia da Costa, no centro da cidade. Teve uma infância saudável e afetiva. Sua Mãe Olga teria ainda mais seis filhos. Apesar da política e dos negócios da família o pai era foi uma figura presente, que fazia questão de reunir a família no almoço e nos finais de semana. Foi nesse ambiente tranquilo e familiar que marcaria a personalidade de Bento Munhoz.

A carreira política do pai, os debates políticos e econômicos do dia a dia, marcaria a formação política de Bento. O pai como médico incentivara seus filhos a estudarem e seguirem carreira profissional. Bento aprendeu a ler aos 5 anos, e já adolescente demonstrou-se um leitor e apreciador dos clássicos gregos e da literatura francesa do século XIX. Estudou no Ginásio Diocesano dos Padres Lazaristas na capital. No colégio tomou gosto pelos escritos de São Tomás de Aquino, que mais tarde um conformaria sua formação tomista. Aprendeu com as leituras de Aquino uma aversão pela agressividade e truculência, em favor do debate intelectual. (REBELO, 2005, p. 16).

O ex-governador acompanhou a prosperidade de Paranaguá no governo de seu pai Caetano Munhoz da Rocha (1908-1916) na prefeitura da cidade, fruto da riqueza do mate. Os impostos recolhidos permitiram um processo em termos de infraestrutura de modernização urbana como a primeira rede esgotos da cidade e uma nova área portuária. Mas a riqueza da indústria do mate foi além de Paranaguá, permitindo também a urbanização da capital.

A família muda-se para a capital em 1915, em função do desejo do pai em alçar novo patamar na política estadual. O Partido Republicano havia indicado Caetano Munhoz da Rocha como vice da chapa do guarapuavano Affonso Alves Camargo, a chapa saiu vitoriosa na eleição a governador da província entre 1920-1928.

Caetano era ligado a indústria de exportação do mate, enquanto que Affonso Camargo, político de Guarapuava, vinha de uma família tradicional proprietária de grandes latifúndios, que estavam presentes no processo de colonização desde o século XVI segundo afirma Zeloi Santos (2005, p. 50) "os primeiros núcleos de moradores que se efetivaram na 5 a Comarca, em meados do século XVI, depois da descoberta da primeiras minas de ouro de Paranaguá, constituíam-se predominante de famílias luso-brasileiras, entre elas família de Antônio de Sá e Camargo", eram detentores de terras no Planalto de Curitiba, nos Campos Gerais (Palmeira), e receberam do príncipe 
regente D. João VI, em 1809, outra gigantesca Sesmaria no município de Guarapuava, região de área pastoril dominada por latifúndios, marcada pela povoação realizada ao custo do extermínio de tribos indígenas.

A ligação entre as famílias Munhoz da Rocha e Camargo, perpassariam os interesses políticos pela união de Bento Munhoz da Rocha Neto com filha de Affonso de Camargo, a senhora Flora Camargo Munhoz da Rocha, então vice-governador na chapa do seu Pai, transformando-se no mesmo grupo familiar com interesses que convergiam e as vezes se chocavam. A união política dos Camargo e Munhoz da Rocha, colocaria Bento na condição de pertencente a oligarquia ligada a República Velha.

\begin{abstract}
Membro da classe dominante paranaense e de uma família tradicional do Estado, que teve destaque no cenário político após o processo de redemocratização de 1946. Bento Munhoz da Rocha foi herdeiro político das oligarquias da República Velha. Seu pai, Caetano Munhoz da Rocha, e seu sogro, Affonso Alves de Camargo, governaram o Paraná no período entre 1916 a 1930. Durante a República Velha, o poder político em nível regional é exercido pelas oligarquias vinculadas à economia do mate e a economia pecuária. Caetano pertencia à oligarquia vinculada à economia da erva-mate, enquanto Camargo pertencia à oligarquia vinculada aos proprietários de terra dos campos gerais, a economia pecuária. Alternado a presidência e a vice-presidência, governaram o paraná de 1916 até a 'Revolução de 1930', pelo Partido Republicano Paranaense. (KUNHAVALIK, 2004, p. 143).
\end{abstract}

A união das famílias produziu êxito político, afinal dominaram o governo do Paraná por entre 1916 a 1930, nos governos de Affonso de Camargo e Caetano Munhoz, de 1951-1955 com o próprio Bento Munhoz e outro braço da família com Ney Braga que foi casado com a irmã de Bento, sendo prefeito de Curitiba com apoio de Bento em 1954-1958 e governador do Paraná entre 1961-1965 e 1979-1982.

\title{
2. Situação Política, Econômica e os Movimentos Sociais (1900-1920) no Paraná.
}

O Estado do Paraná nos anos de 1900-1920, apresentava uma dispersão do poder político e econômico entre o litoral (Paranaguá, Antonina e Morretes), o Sul (Lapa), região do Paraná Tradicional (Castro, Palmeira, Ponta Grossa e Guarapuava) e a capital Curitiba. Seguidos de Clevelândia e Palmas. O início do século XX, marcou um período de transição econômica com a estagnação da indústria do mate, o surgimento do ciclo da madeira e do café no norte do estado a partir dos anos de 1930. (KUNHAVALIK, 2004, p. 143).

O Paraná apresentava uma baixa densidade demográfica segundo censo de 1900, com pouco mais de 327 mil habitantes, distribuídos em 31 municípios. A baixa ocupação populacional oficial, foi marcada pela opção ideológica da invisibilidade da presença indígena e Negra no Estado. As terras paranaenses segundo Parrelada (2017) foram ocupadas pelas populações indígenas a mais de 12000 
anos, sendo dizimados em sua maioria, enquanto os sobreviventes foram reclusos as reservas, além ainda dos remanescentes de escravos que fugiam das fazendas formando comunidades quilombolas.

Atualmente existem no Estado aproximadamente 9015 Indígenas, habitando 85.264,30 hectares de terra. Está área está distribuída em 17 terras abrigando as etnias Kaingang, Guarani e 6 remanescentes do povo Xetá. O Paraná apresenta 86 comunidades de quilombolas que foram reconhecidas pelo governo de Estado em 2005, após levantamento organizado Grupo de Trabalho GT Clóvis Moura com apoio técnico do Instituto de Terras, Cartografia, Geociências do Paraná. (ITCG, 2008).

O contexto econômico paranaense no último quartel do século XIX, marca o momento de transformações com o advento do primeiro surto de industrialização de Curitiba, e o início do declínio das exportações do mate, principal produto do estado durante o século XIX. Este ciclo havia produzido uma elite econômica e política que comandava o Paraná, na qual se inseria família Munhoz da Rocha. Mas que enfrentava nas primeiras décadas do século XX, a retração do mercado de exportações, fechamento de fábricas e a estagnação do setor, aliado ao surgimento de um novo ciclo econômico, o café. (PADIS, 1981, p. 47-63).

As mudanças econômicas se tornaram intensas nas três primeiras décadas do século XX, que afetariam ambiente político na capital do estado. Nesse momento de transformações significativas na história paranaense, a família Munhoz da Rocha, ligada ao negócio do mate, encontrava-se no centro do poder estadual entre 1916 - 1930. (KUNHAVALIK, 2004, p. 20).

A dupla de políticos eram os governantes no período da Guerra do Contestado ${ }^{2}$ e de outro importante conflito social, a greve de operários de junho 1917. Contextualizaremos o Movimento Social intitulado Greve de 1917, pois este interferiu no cotidiano da cidade com repercussões junto as classes sociais mais abastadas da sociedade curitibana.

O evento iniciou em São Paulo e atingiu o Paraná no mês de julho. Esse movimento social tinha como bandeira melhores salários e condições de trabalho. Entre as reivindicações estavam a jornada de oito horas, turno de seis horas para período noturno, redução dos gêneros alimentícios, do aluguel das casas particulares e higiene nas fábricas. No Paraná o conflito foi muito organizado, com a paralisação de transporte de ambulância, energia, transporte público, as fábricas de fundição chegando a destruir as pontes que ligavam Curitiba a Santa Catarina, aos Campos Gerais e a São Paulo isolando a cidade, motivo de grande crítica da imprensa da época.

\footnotetext{
${ }^{2}$ A Guerra do Contestado foi vista pela elite paranaense com desconfiança, acreditava-se que as elites rurais catarinenses haviam insuflados os Caboclos a revolta com objetivo de tirar vantagens territoriais aos catarinenses. Tese infundada pela historiografia do movimento que mostrou ser um evento bastante complexo, com interesses entrelaçados que incluíam a luta pela terra, a construção da estrada de ferro, a exploração das margens da ferrovia, questão religiosa, o messianismo, coronelismo, jagunços a serviço das madeireiras e fazendeiros. Enquanto a situação era caótica na região do conflito, o jovem Bento observava a guerra pela leitura da imprensa curitibana que ignorava essas situações atribuído a causa do conflito e da violência a um bando de fanáticos religiosos e foi por essa manipulação que a notícia da morte do coronel João Gualberto causou uma enorme comoção, morto em batalha no Irani. (REBELO, 2005, p. 21).
} 
Affonso Camargo, governador de então, explicou os motivos da greve de 1917, em Curitiba, segundo Moraes (2017, p. 14):

\begin{abstract}
$\mathrm{O}$ anno que vem a findar foi prenhe de acontecimentos que muito impressionaram a opinião pública, disse o então Presidente da Província do Paraná, Affonso Alves de Camargo, fazendo referência ao ano de 1917. E realmente foi um ano conturbado não só para o Paraná, mas para o mundo. A Primeira Guerra Mundial acabava de suscitar nos brasileiros um patriotismo que via na figura do estrangeiro um inimigo iminente. A guerrilha do Contestado dando vitória a Santa Catarina (local de forte imigração alemã) se aliou ao forte antigermanismo dos paranaenses, causando mal-estar dentro do estado. Além disso, ainda a Grande Guerra trazia consequências materiais para os paranaenses: a falta de matéria-prima e de mercados externos trazia principalmente às zonas urbanas forte carestia entre os homens pobres.
\end{abstract}

Portanto, para a autoridade governamental fatores externos teriam produzido as dificuldades experimentadas pela classe trabalhadora, em uma tentativa de isentar seu governo e a estrutura concentradora de riquezas para uma elite econômica em detrimento da maioria da sociedade.

O resultado deste processo foi alteração do dia a dia da cidade, com intensa mobilização dos operários, algo incomum até aquele momento histórico, fato que representava a transformação que a industrialização, a imigração, a organização sindical dos operários, da atuação política dos anarquistas levaram ao Paraná conforme descrito por Moraes (2017, p. 15) "Dia 19 de julho começaram os primeiros piquetes, e os grevistas andavam pela cidade espalhando panfletos e fazendo discursos para convencerem os trabalhadores a aderir ao movimento.” A adesão à greve chegou aos trabalhadores do setor de energia, afetando a distribuição de eletricidade, a milhares de residências às escuras. As autoridades de segurança tentam controlar a situação com uso da força afirma Moraes (2017, p. 15) "Numa tocaia a polícia atira tiros de festim nas massas, que avançam para a polícia e retornam com tiros de pistolas e surras de cacetes. Todo o sistema ferroviário estaria parado, e de que haviam grevistas em outros locais do estado". Os trabalhadores tinham como estratégia isolar a cidade de com qualquer comunicação externa, dinamitando os trilhos da ferrovia que ligava Curitiba ao litoral, arrancam fios de telefone, ainda afetam a distribuição da água e chegam até a lançar bomba em bondes elétricos para forçar sua retirada de circulação.

Esse movimento social ganhou as ruas em grandes manifestações públicas de operários, que foram classificadas como baderna sendo reprimidas pela força policial. O quadro apesar de controlado pelas autoridades vai influenciar as leituras do jovem estudante mais tarde professor de sociologia e história da América da UFPR.

A organização dos trabalhadores, em especial, a greve de 1917, aliado a Revolução Russa, colocou a elite política em alerta e foi presenciando pelo adolescente Bento Munhoz da Rocha pela agitação das ruas, das críticas dos jornais e dos comentários que presenciava. Não há dúvida que contribuiu de alguma forma para a formação de seus conceitos sobre o mundo do trabalho. 


\section{O Contexto histórico dos Anos 1920 e a Formação Acadêmica de Bento Munhoz da Rocha}

O contexto histórico nos anos 20 do século XX, foram marcados pela agitação política, econômica e social. Período de formação do ensino médio de Bento Munhoz da Rocha, no Ginásio Diocesano administrado pelos padres Lazaristas e do curso de Engenharia Civil na Universidade do Paraná, atual Universidade Federal do Paraná. Bento foi segundo Rebelo (2005, p. 14) um "leitor voraz de jornais, revistas, de clássicos gregos e a literatura francesa do século XIX (admirador de Anatole France - 1844-1924)". Portanto, as notícias, editoriais e análises desses movimentos políticos, econômicos e sociais faziam parte de suas leituras e reflexões, contribuindo no processo de formação do intelectual que anos mais tarde se configuraria. Alguns desses acontecimentos foram fundamentais na história universal, brasileira e paranaense.

Durante a década 20, ocorreram transformações econômicas, políticas e sociais de relevância no país e no mundo, este tópico irá se referir preponderantemente a elas, foram anos marcados pelo período "Entre Guerras Mundiais; Crise Econômica na Europa; o fortalecimento dos Estados Unidos como a grande potência econômica e militar do ocidente; no Brasil, a crise dos preços do Café principal produto brasileiro entre 1921-1922; a Semana de Arte de 1922; o Movimento Tenentista de 1922; O surgimento do Partido Comunista do Brasil - PCB; A Coluna Prestes que percorreu o país incluindo o estado do Paraná no oeste e norte; o surgimento da União da Repúblicas Socialistas Soviéticas (U.R.S.S) em 1922 e a expansão Socialista; a Crise Capitalista de 1929 e Finalmente a Revolução de 1930 que levou ao poder Getúlio Vargas, iniciando um governo de 15 anos, que marcariam a política, a economia e a sociedade brasileira.

Foram anos de intenso conflito político, social, cultural e econômico no mundo, no país e com repercussões nas terras paranaenses. Do ponto de vista econômico, a década de 1920, foi marcada por altos e baixos. Nos primeiros anos a baixa do café afetou nossa economia, pois o produto era o carro chefe de nossas exportações, produzindo suas consequências como o aumento da inflação e uma crise fiscal fruto da política de Valorização do Café, que desvalorizava a moeda brasileira para favorecer os exportadores, mas como os bens de consumo direto eram em sua grande importados aumentava seus preços a comerciantes e consequentemente para os consumidores. Após esses momentos críticos da economia que inclusive levaria a uma crise com a eleição de Arthur Bernardes representante desse modelo econômico, o país acabou superando essas dificuldades e presenciou um crescimento econômico expressivo até a Grande Crise de 1929. (FERREIRA, 2003).

A década de 20 representou um período de maior organização da classe trabalhadora, conflitos de interesses entre frações da burguesia; alta de preços; reivindicações por mais direitos sociais e expansão do movimento revolucionário tenentista e da Coluna Prestes nesse mesmo ano, e, ao final do período, na Revolução de 1930. A expansão das idéias socialistas e o surgimento e fortalecimento 
da União Soviética amplificaram caldeirão político e econômico dos anos 20, estiveram no centro dos debates acadêmicos no período de formação de Bento Munhoz, que como leitor voraz, tinha conhecimento dos fatos que ocorriam no país e no mundo, e o contribuindo na formação intelectual e na concepção de país que deseja.

Em 1929, Bento Munhoz da Rocha iniciou-se sua carreira profissional como engenheiro, na função de diretor técnico da Siderurgia Gonçalves de Sá ou Companhia Indústria Brasileira, com salário de 3 contos de réis. Foi nesse período que começou a publicar na imprensa local, os primeiros artigos o tema recorrente foi o Autoritarismo e Democracia, "demonstrando que estava atento ao embate entre os regimes liberais e seus antípodas totalitários, aos quais já alinhara a Itália, desde a Marcha de Mussolini sobre Roma “influência do período com a ascensão de Benito Mussolini na Itália em 1922. (REBELO, 2005, p. 36).

A opção pelo curso de Engenharia Civil, nos seus escritos não aparece o motivo da escolha, mas o desgaste político enfrentado pelos políticos ligados a chamada República Velha pode ter sido decisivo para a escolha, pois como observou GOMES (1994, p. 4) “A Modernização do país que, segundo os diagnósticos dos anos 20 e 30, já estava em curso e devia ser acelerada, exigia a presença de homens com formação distinta. O Brasil precisava não de "profissionais na política", mas de profissionais com formação técnica específica”, portanto, o poderia ter sido uma estratégia de Bento Munhoz para fugir do rótulo de "político profissional" inicia uma carreira de engenheiro, o que reforçava o discurso da formação e competência técnica.

Ainda sobre esse movimento que tomaria corpo afirma Gomes (1994, p. 4) "Pouco a pouco, e não sem enfrentamentos, o 'bacharelismo' e a 'política' vão sendo compreendidos como sinônimos e identificados como atividades retrogradas e geradoras de um discurso retórico distante da 'realidade nacional' e afastado da moderna ação intervencionista do Estado". A imagem do técnico como profissional, competente, administrador, transformado em uma espécie de salvador da pátria, para tanto seria necessário obviamente um afastamento da política tradicional, exatamente pela capacitação técnica especializada, refutando a tradição humanista da Ilustração. Cabe ressaltar que foi nesse período que nossas primeiras universidades são organizadas (Universidade de São Paulo USP, Universidade do Distrito Federal - UNB) e ao mesmo tempo são implementados fugindo dos tradicionais cursos de Medicina, Engenharia e Direito.

Essa possibilidade da opção técnica seria uma estratégia política de uma nova elite que acessando postos chaves do aparelho do Estado, possibilitaria participar na definição de políticas econômicas e sociais e na administração direta, ou na gerência de empresas e instituições vinculadas ao governo. Esse quadro é pertinente ao processo de transformação que passava o Estado brasileiro, que muitas vezes contraditórias, pois são reconhecidos como articulações progressistas a época à manutenção de outras claramente tradicionais. Ao que parece foi o caminho traçado por Bento, ser 
reconhecido primeiramente como um acadêmico, somente após adentar ao universo político partidário. (GOMES, 2004, p. 6).

A relação de ambiguidade fica evidente no casamento com Flora Camargo, em abril de 1929. Ela filha de Affonso Alves de Camargo, que fora presidente do Estado do Paraná entre 1916-1920, tendo como vice-presidente seu pai Caetano Munhoz da Rocha. Os Camargo eram representantes da velha oligarquia dos grandes proprietários de terras do chamado Paraná Tradicional, da região de Guarapuava, tendo sua genealogia entrelaçada ao poder desde as primeiras sesmarias distribuídas por D. João VI, em 1809. Evidentemente, que a contradição não estava no casamento com a sra. Flora, mas as relações pessoais e políticas advindas desta união, com uma das famílias mais tradicionais da política paranaense durante a República Velha, essas contradições serão analisadas pois foram percebidas em sua época e serviram de tema no debate político com seus adversários. A aliança entre o representante da burguesia industrial do Mate, Dr. Caetano Munhoz da Rocha e o representante da oligarquia latifundiária Affonso Camargo, evidenciavam a crise econômica que havia abatido a indústria do Mate e o setor da tradicional agropecuária paranaense, que ameaçava o poder o domínio da classe dominante. As mudanças econômicas com o avanço da cafeicultura e suas relações com o capital Paulista evidenciava a chegada de um novo grupo político e econômico no cenário regional. (KUNHAVALIK, 2004).

Essa relação de ambiguidade estabelecida pelo intelectual em relação a sua classe social e a sociedade foi analisada em Bourdieu (2013, p. 192) a "situação de dependência material e impotente politicamente diante das frações dominantes da burguesia de onde a maioria de seus membros se origina e da qual participam se não por suas relações familiares e círculos de amigos, pelo menos por seu estilo de vida" Portanto para Bourdieu (2013, p. 192) a preservação do modo de vida aproximavam a elite tradicional dominante e a burguesia mesmo diante das contradições no interior das classes pois estariam "mais próximo do estilo da burguesia do que do estilo das classes médias vê-se forçada a manter uma relação ambivalente tanto com as frações dominantes da classe dominante como com as classes dominadas, e a compor uma imagem ambígua de sua posição na sociedade e de sua função social".

Essa relação com frações da burguesia detentora do poder regional certamente influenciaria em sua formação política e moral. A opção intelectual permitiu a Bento Munhoz incrementar novos conhecimentos, relações políticas e sociais. Evidenciava essa nova situação na participação das reuniões com intelectuais Católicos, onde buscava respostas morais diante do avanço das ideias comunistas que eram debatidas e estudadas na academia. Dessas reuniões resolveram fundar o Círculo Bandeirantes ${ }^{3}$ a convite do padre Luiz G. Miele, que reuniu vários intelectuais com a ressalva

\footnotetext{
3 “Aconteceu em 1929, quando um grupo de intelectuais paranaenses, a maioria de Curitiba, com grandes e louváveis ambições, lançou a semente dessa instituição cultural. Entre esses distintos intelectuais, estavam: Antonio Rodrigues de
} 
de confessarem a religião Católica. Bento foi um dos sócios-fundadores convidados. O Círculo Bandeirantes foi a uma referência para a formação de uma geração de intelectuais seguidores das idéias de São Tomaz de Aquino, como afirmou o próprio Bento Munhoz da Rocha (1939, p. 3) "Enamorado da unidade e da ordem, disseminou, em curso regular, preceitos definitivos do Tomismo. Pregou na hora delirante dos imediatismos e dos êxitos, o primado eterno do espírito", e complementa a visão sobre os valores do Tomismo que segundo Rocha (1953, p. 2):

Foi este um grande benefício que devo ao velho Santo Tomaz de Aquino, pela disciplina espiritual e pela liberdade mental que me conferiu no julgamento do pensamento contemporâneo, como do pensamento de todas as épocas. É evidente que a filosofia não é apenas uma doutrina de formação de idéias, mas é, acima de tudo, uma concepção de vida e do mundo.

Para corroborar nos anos de 30, Bento Munhoz da Rocha participou de vários cursos de filosofia no Círculo Bandeirantes que foram ministrados pelos padres Luis Gonzaga Miele e Jesus Ballarin, essa formação teve forte influência sobre sua formação em ciências humanas, sua opção pela carreira acadêmica, além formar um orador, pois em uma das atividades do curso, os alunos deviam discursar sobre temas diversos. Para Pe. Luis Miele, a criação do círculo de estudos teve como objetivo combater a proliferação das ideias modernistas destruidoras dos valores cristãos em que a existiria uma necessidade do pensamento orientador das almas que se devem enrijar na escola do caráter inflexível, do dever e das responsabilidades sociais, face à anarquia reinante no mundo das inteligências. Para os representantes da Igreja seria necessário preparar intelectuais cristãos diante do avanço das ideias comunistas e do liberalismo laico "Frente à moda intelectual modernista, que se caracteriza por uma atitude iconoclasta e devastadora dos valores tradicionais, o Círculo almejava “armar os seus sócios para a conquista pacífica da verdade.

A preocupação da Igreja Católica de Curitiba em estruturar uma instituição para intelectuais Católicos deve ser compreendida na perspectiva do contexto político e ideológico daquele momento histórico. Período marcado pela ascensão e disseminação das ideias marxistas, culminado na formação da União Soviética (U.R.S.S) que patrocinava a internacionalização dos princípios marxistas, que atingiram países como o Brasil. Portanto, podemos afirmar que foi uma reação de investir para conquistar intelectuais que defendessem os conceitos doutrinários da Igreja, que reconhecia a força das idéias comunistas e seu avanço como ameaça ao catolicismo na Europa e no

Paula, Benedito Nicolau dos Santos, Bento Munhoz da Rocha Neto, um jovem intelectual, grande nome do Paraná; Carlos Augusto de Brito Pereira; José Farani Mansur Guérios; Padre Luis Gonzaga Miele; José Loureiro Fernandes; José de Sá Nunes; Liguarú Espírito Santo; Pedro Ribeiro Macedo da Costa e Waldomiro Augusto Teixeira de Freitas.” (PUC-PR, 2017. Círculo Bandeirantes. Disponível em http://www.pucpr.br/circuloestudos/index.php, acesso em 01 de junho de 2017.) 
mundo, pois seus conceitos já haviam influenciado naquele momento histórico os movimentos operários europeus e a organização de partidos políticos defensores da ideologia Marxista que começava a surgir com força no país.

Essas influências na formação do intelectual Bento, foi esclarecida pelo próprio em entrevista à revista Divulgação Paranaense, em 1963:

\begin{abstract}
Não posso esquecer que foi um tomista quem firmou em mim a convicção da necessidade de uma referência doutrinária com que se pudesse disciplinar a Inteligência diante da multiplicidade de solicitações do pensamento moderno. Foi o grande professor João Perneta, positivista e profundo conhecedor da obra de Comte, possuidor, portanto, de uma definição diante da indefinição, que, através de seu curso de Filosofia Primeira, consolidou em meu espírito a necessidade de continuação dos estudos filosóficos que eu já havia iniciado, como um desdobramento racional de minhas raízes religiosas. O Tomismo me concedeu a definição intelectual que haveria de permitir navegar com relativa tranquilidade no mar grosso do pensamento contemporâneo.
\end{abstract}

Para Duriguetto (2014), Gramsci analisou o papel dos intelectuais orgânicos pertencentes as classes dominantes, pois se reconheciam nestas fossem proprietários rurais, empresários, comerciantes e industriais, dando direção política aos interesses de classe, o caso do ex-governador deve ser compreendido como intelectual pertencente a extrato social econômico e politicamente dominante e utilizou-se dos conhecimentos para perpetuar a visão de mundo burguesa urbano industrial considerada mais progressista época como afirma Duriguetto (2014, p. 270):

\begin{abstract}
Por intelectuais, deve-se entender [...] todo o estrato social que exerce funções organizativas em sentido lato, seja no campo da produção, seja no da cultura e no político-administrativo [...]. Para analisar a função político-social dos intelectuais, é preciso investigar e examinar sua atitude psicológica em relação às classes fundamentais que eles põem em contato nos diversos campos: têm uma atitude "paternalista" para com as classes instrumentais ou se consideram uma expressão orgânica destas classes? Têm uma atitude "servil” para com as classes dirigentes ou se consideram, eles próprios, dirigentes, parte integrante das classes dirigentes?
\end{abstract}

O que não significa que no interior da classe não exista as contradições que apresentaram durante o governo entre o discurso e os artigos onde defende a pequena a propriedade e a reforma agrária, mas quando as coloca em prática reprimi com força policial os caboclos de origem como afirma Oikawa (2011, p. 51) "nordestina, mineira e paulista que viviam como posseiros, atraídos em busca de lote, pois deve-se obedecer apenas uma regra: derrubar a floresta, plantar, produzir e viver durante sies anos, o posseiro pode requerer o título definitivo da propriedade" e, em contrapartida defendeu os colonos descendentes de italianos e alemães que também encontravam-se nas mesmas condições recebendo um tratamento diferente do governo estadual. Essa sutileza será relevante para o trabalho para compreender o processo de escolha do modelo de agricultor para implementar o um novo modelo agrário, o imigrante, em detrimento dos nacionais. 
Bento Munhoz quando analisa o processo colonial justifica os motivos do sucesso de Witmarsum (Palmeira), e a escolha dos agricultores de origem Alemã estaria principalmente no comportamento dos colonos dedicados ao exclusivamente ao labor deixando implícito inexistência destes valores nos caboclos nacionais quando afirma Rocha (1968, p. V) "Sem conflitos, sem espoliações e que pode abrir os olhos de nossos dirigentes de os matizes ideológicos... a nova experiência foi possível devido a existência de um comportamento exigido para o desenvolvimento", Ainda no mesmo documento Bento Munhoz da Rocha (1968, p. V) compara que seria a falta de experiência e dedicação ao trabalho que faria a diferença no processo de desenvolvimento desigual das regiões do país, afirmando que "talvez resida aí o maior conflito brasileiro de hoje, entre suas regiões diferenciadas quanto ao seu desenvolvimento e quanto ao comportamento exigido para o desenvolvimento".

\section{Considerações Finais}

Essas questões ideológicas são importantes para compreender as ações do governador Bento Munhoz da Rocha, em áreas como saúde criando os postos de puericultura, assistência do trabalhador Rural, criação de escolas, investimentos em rodovias, ferrovias e portos, apoio ao cooperativismo e a industrialização do campo, pois todas foram implementadas a partir da moralidade católica adquirida da formação Tomista no Círculo Bandeirantes e da visão liberal de compreender o universo político e econômico, da defesa da liberdade de pensamento, sem perseguições como ocorridas aos defensores de ideias marxistas.

Portanto sua formação familiar, moral e política o transformaram em defensor da democracia Liberal, sem se esquecer da defesa dos direitos dos trabalhadores a partir dos conceitos a defesa das teses defendidos pela Igreja Católica, conhecidas como Doutrina Social expressa na Encíclica Rerum Novarum. A organização do sistema cooperativismo agro-industrial, o apoio aos agricultores para que estivessem organizados em cooperativas para resistirem ao mercado capitalista. Demostra a formação de orientação católica em contraposição ao liberalismo onde o capital não tenha restrições de atuação e que tudo deveria ser corrigido pelo mercado.

Como intelectual orgânico estabelecido junto a uma certa elite política advinda da época seu pai Caetano Munhoz Rocha, percebeu as mudanças que ocorriam no estado e no país, reorganizou as forças, como forma de integrar o estado não somente em relação a questão física, qual a construção de estradas e linhas de transmissão, mas de princípios católicos em que apresentava a lideranças de várias do estado como forma de ampliar uma elite do Paraná Tradicional, para uma elite paranaense católica. 


\section{REFERÊNCIAS}

BOURDIEU, Pierre. A Economia das trocas simbólicas. São Paulo: Perspectiva, 2013, p. 192.

GOMES, Angela de Castro. Novas Elites Burocráticas.IN: Engenheiros e Economistas: novas elites burocráticas. Rio de Janeiro: FGV, 1994.

DURIGUETTO, Maria Lucia. A questão dos intelectuais em Gramsci. IN: Revista do Serviço Social e Sociedade. São Paulo: Cortez, n. 118, p. 265-293, abr./jun. 2014.

FERREIRA, Marieta de Moraes; PINTO, Surama Conde Sá. A Crise dos anos 1920 e a Revolução de 1930. IN: FERREIRA, Jorge; DELGADO, Lucilia de Almeida Neves (Org). O Brasil Republicano: O tempo do liberalismo excludente. Rio de Janeiro: Civilização Brasileira, 2003.

INSTITUTO DE TERRAS, CARTOGRAFIA E GEOCIÊNCIAS. Terra e Cidadania. Curitiba: ITCG, 2008.

KUNHAVALIK, José Pedro. Bento Munhoz da Rocha Neto: trajetória política e gestão no governo do Paraná. Curitiba: SETI, 2004.

MORAES, Anne Caroline da Rocha de. Movimentos subversivos e attentatorios à ordem: uma análise da opinião do Presidente da Província do Paraná a respeito da Greve Geral de 1917, em Curitiba. IN: Revista Vernáculo. Curitiba, UFPR, vol. 39, 2017.

OIKAWA, Marcelo. Porecatu: A Guerrilha que os comunistas esqueceram. São Paulo: Expressão Popular, 2011.

PADIS, Pedro Calil. Formação de uma Economia Periférica: O caso Paraná. São Paulo: Hucitec, 1981.

PARANÁ. SECRETARIA DE ESTADO DA EDUCAÇÃO. Terras Indígenas do Paraná. Curitiba: 2016.

PARRELADA, Cláudia. Arqueologia do Paraná. Curitiba: Museu Paranaense. Disponível em http://www.museuparanaense.pr.gov.br/modules/conteudo/conteudo.php?conteudo=31. Acesso dia 15 junho 2017.

PUCPR. Círculo Bandeirantes. Disponível em http://www.pucpr.br/circuloestudos/index.php, Acesso dia 01/06/2017.

REBELO, Vanderlei. Bento Munhoz da Rocha: O intelectual na correnteza política. Curitiba: Imprensa Oficial, 2005.

REVISTA DIVULGAÇÃO PARANAENSE. Entrevista de Bento Munhoz da Rocha. Curitiba: editora Arnaud Velozo, ed. set/ 1963.

ROCHA, Bento Munhoz da. Círculo de Estudos Bandeirantes. Curitiba: Circulo Estudos Bandeirantes, Tomo II, n. 1, p. 3 -5, setembro 1939. 
ROCHA, Bento Munhoz da. Oração proferida pelo Sr. Governador do Estado no almoço oferecido aos participantes do II Congresso Brasileiro de Filosofia. Curitiba: Museu Paranaense, TOMO AC 156969 , p. 2, 20/09/1953.

ROCHA NETO, Bento Munhoz da. Novas Experiências nos Campo Gerais. Prefácio. In: BALHANA, Altiva; MACHADO, Brasil Pinheiro (ORG.). Campos Gerais: Estruturas Agrárias. Curitiba: UFPR, 1968.

SANTOS, Zeloi Aparecida Martins dos. Visconde de Guarapuava: Um personagem na História do Paraná. 208 f. Tese (Doutorado em História) - Setor de Ciências Humanas - UFPR, 2005. 